\title{
Impact of Solar Panel Orientation on the Integration of Solar Energy in Low-Voltage Distribution Grids
}

\author{
Joannes I. Laveyne $\mathbb{D}^{\mathrm{D}},{ }^{1}$ Dimitar Bozalakov, ${ }^{1}$ Greet Van Eetvelde, ${ }^{2}$ and Lieven Vandevelde ${ }^{1}$ \\ ${ }^{1}$ Electrical Energy Laboratory (EELAB), Department of Electrical Energy, Metals, Mechanical Constructions and \\ Systems (EEMMeCS), Ghent University, Technologiepark-Zwijnaarde, 1319052 Ghent, Belgium \\ ${ }^{2}$ Energy \& Cluster Management, Department of Electrical Energy, Metals, Mechanical Constructions and Systems (EEMMeCS), \\ Ghent University, Technologiepark-Zwijnaarde 131, 9052 Ghent, Belgium
}

Correspondence should be addressed to Joannes I. Laveyne; joannes.laveyne@ugent.be

Received 11 October 2019; Revised 27 December 2019; Accepted 10 January 2020; Published 1 February 2020

Guest Editor: Marco Rivera

Copyright (c) 2020 Joannes I. Laveyne et al. This is an open access article distributed under the Creative Commons Attribution License, which permits unrestricted use, distribution, and reproduction in any medium, provided the original work is properly cited.

\begin{abstract}
In Belgium, and many other countries, rooftop solar panels are becoming a ubiquitous form of decentralised energy production. The increasing share of these distributed installations however imposes many challenges on the operators of the low-voltage distribution grid. They must keep the voltage levels and voltage balance on their grids in check and are often regulatory required to provide sufficient reception capacity for new power producing installations. By placing solar panels in different inclinations and azimuth angles, power production profiles can possibly be shifted to align more with residential power consumption profiles. In this article, it is investigated if the orientation of solar panels can have a mitigating impact on the integration problems on residential low voltage distribution grids. An improved simulation model of a solar panel installation is constructed, which is used to simulate the impact on a residential distribution grid. To stay as close to real-life conditions as possible, real irradiation data and a model of an existing grid are used. Both the developed model as the results on grid impact are evaluated.
\end{abstract}

\section{Introduction}

The ever growing interest in renewable energy sources across the world is driven by numerous factors, notably the increasing awareness of environmental issues, the depletion of conventional indigenous energy sources, and the progress of technology leading to decreasing installation costs. The liberalisation of the energy markets in large parts of the world has empowered private, commercial, and public parties alike to contribute to the global renewable energy production by installing Decentralised Renewable Energy Systems (DRES) at the local level. The primary energy sources of these systems are often solar, wind, combined heat, and power or hydropower. Flanders, the Northern part of Belgium, has seen a spectacular increase in the number of solar or PhotoVoltaic (PV) systems, from virtually none before 2006 to more than 242.000 at the end of 2016 . 97\% of all installations are domestic installations with a capacity smaller than $10 \mathrm{kWp}$ and are connected to the local low voltage (LV) grid. Total installed capacity has reached more than $2.2 \mathrm{GW}$ by the end of 2018 [1].

The variable nature of DRES poses challenges to their grid integration, especially at high concentrations on the LV grid such as is the case with residential rooftop PV. High concentrations of PV systems on a LV feeder combined with the mismatch of the PV production curve with the typical residential load profile can lead to voltage disturbances along the feeder or congestion of the feeder or substation [2-5], decreasing the power quality of the grid.

To mitigate these problems, Distribution System Operators (DSO) size their grids according to the peak power of each individual DRES installation and load connected to the feeder, effectively oversizing the grid dimensions. On-load tap changers at the substation provide another mitigation effort. Both options are however not preferable on a wide scale because of the financial aspects [6]. Active 
power curtailment, where DRES installations are taken offline when the feeder gets congested, is a more cost-effective solution but often leads to large voltage oscillations disturbing the grid [7].

Most DRES are connected to the grid through powerelectronic converters. Innovative converter topologies [8] or control strategies to mitigate the impact of each DRES installation on the grid or to even provide grid-supporting features have recently been developed. These can be based on reactive power injection to support the grid voltage [9], "soft" power curtailment using voltage droop control [10], or a combination of both [11]. These solutions use the existing converter hardware and can be implemented at low cost. However, because the grid codes currently do not require these advanced control strategies, there is little incentive for converter manufacturers to implement them in their products.

In this article, a possible solution that does not rely on possibly expensive hardware or software upgrades is investigated. It has already been shown that different horizontal and vertical orientations of $\mathrm{PV}$ panels can benefit the electricity system as a whole by increasing the coincidence between PV production and electricity consumption [12]. Indeed, by varying the orientation, the typical PV production peak at noon can be flattened, and power production can be shifted towards the morning and early evening, better matching the typical residential consumption profile. The effect of different orientations of the panels of the PV installation on the energy production curve and the accompanying impact on the distribution grid will be investigated. This paper contributes to the existing research in the following way:

(i) The effect of orientation of PV panels on congestion and voltage profile of the local LV grid is examined

(ii) A methodology for calculating the yield and production curve of arbitrarily oriented PV systems based on a limited number of required parameters and using an anisotropic-all-sky model better suited for Western-European conditions than the prevalent isotropic model is presented

(iii) Simulations based on real residential load profiles and grid parameters provide a realistic and accurate validation of the research objectives

In this article, the effects are tested and evaluated for a Belgian case. However, the methodology that is valid for any arbitrarily chosen location of irradiation data is available.

The rest of the article is structured as follows. The following section describes the improved model used to calculate the yields of arbitrarily oriented PV panels based only on two irradiation parameters and one temperature parameter, and specifications found in the datasheet of any PV panel. Correspondingly, the third section discusses the PV inverter model and evaluates the accuracy of the combined PVinverter model by comparing them to real-life yield measurements. The section afterwards introduces a grid model representing a typical European residential LV feeder. After the presentation of the grid model, the results on grid impact

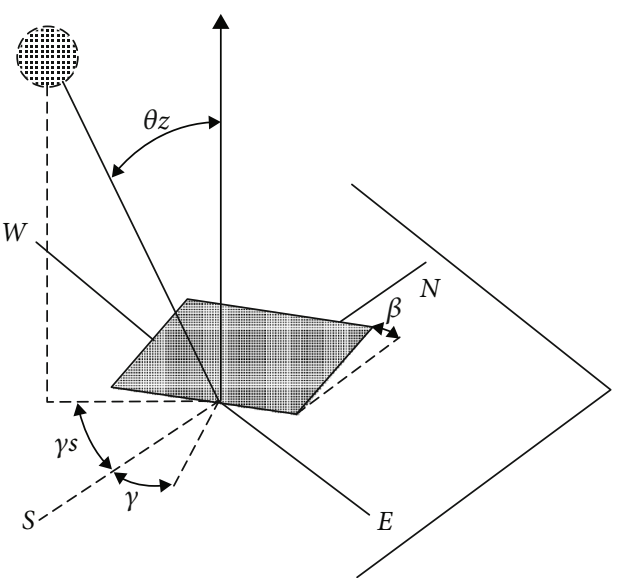

Figure 1: Direction of beam radiation and its associated angles.

and voltage profile along the feeder by varying the PV panel orientations of the connected DRES installations are discussed. Finally, the last section presents the conclusions of this investigation and some suggestions for further research.

\section{PV Model}

2.1. Solar Irradiance. The output of a PV system is dependent on the amount of solar irradiance received by the active surface of the PV panels, with the irradiance having a direct (beam) and a diffuse component [13]. The intensity of the direct beam radiation is highly dependent on the incident angle $\theta$, which is the angle of the sunbeam on the surface of a PV panel to the normal of that surface. This geometric relationship can be described in terms of several angles [14], as shown in Figure 1 adapted from [15].

$\beta$ is the tilt angle of the surface of the PV panel to the horizontal; $\theta_{z}$ is the zenith angle, the angle between the vertical and the sunbeam; $\gamma$ is the surface azimuth angle, the angle between the south and the normal of the PV panel surface as projected on the horizontal plane, with east of south being negative and west of south being positive; and $\gamma_{s}$ is the solar azimuth angle, similarly to $\gamma$ the angle between the south and the sunbeam as projected on the horizontal plane.

Simple trigonometry allows us to calculate the incident angle $\theta$ as

$$
\cos \theta=\cos \theta_{z} \cdot \cos \beta+\sin \theta_{z} \cdot \sin \beta \cdot \cos \left(\gamma_{s}-\gamma\right) .
$$

To calculate the intensity of the diffuse irradiation on the PV panel, this paper uses an adapted version of the anisotropic-all-sky model proposed in [15] called "all-sky distribution," instead of the more straightforward isotropic model commonly used in literature. Isotropic models provide accurate calculations of diffuse radiation on tilted surfaces under overcast skies but tend to underestimate during clear skies. Conversely, models assuming anisotropic distribution perform well under clear skies but overestimate under overcast skies. Because Belgium has both clouded and clear sky situations throughout the year, the all-sky distribution used in this paper combines both isotropic and anisotropic assumptions for maximum accuracy. 
The total irradiation on the tilted surface is calculated by summing the intensity of the beam irradiation and diffuse irradiation:

$$
\begin{aligned}
G_{t}= & \frac{\left(G_{h}-G_{d h}\right)}{\cos \theta_{z}} \cdot \cos \theta+G_{d h} \cdot\left[\frac{1+\cos \beta}{2}\right] \\
& \cdot\left[1+F \cdot \sin ^{3} \frac{\beta}{2}\right] \cdot\left[1+F \cdot \cos ^{2} \theta \cdot \sin ^{3} \theta_{z}\right],
\end{aligned}
$$

with

$$
F=1-\left(\frac{G_{d h}}{G_{h}}\right)^{2}
$$

where $G_{t}$ is total irradiation on the tilted surface of the PV panel in $\mathrm{W} / \mathrm{m}^{2}, G_{h}$ is the total irradiation on a horizontal surface, and $G_{d h}$ is the total diffuse irradiation on a horizontal surface.

The last two terms in the equation represent the anisotropic distribution. During overcast skies, when most of the total irradiation is in the form of the diffuse component, parameter $F$ becomes zero making the model revert to the isotropic distribution. When diffuse radiation is present, the model tends to the isotropic variant.

2.2. PV Panel Output. With total irradiance $G_{t}$ known, the power output of a PV panel with known power rating and efficiency can be calculated. In this article, we use a modified version of the PV model developed by [16] as described in [17], in which the power output is only dependent on $G_{t}$ and PV module temperature $T_{\text {mod }}$ :

$$
P_{\mathrm{DC}}\left(G_{t}, T_{\mathrm{mod}}\right)=P_{\mathrm{STC}} \cdot \frac{G_{t}}{G_{\mathrm{STC}}} \cdot \eta_{\mathrm{rel}}\left(G^{\prime}, T^{\prime}\right) \cdot \eta_{\text {sys }},
$$

where $P_{\mathrm{DC}}$ is the power output of the PV panel under conditions $G_{t}$ and $T_{\text {mod }}, P_{\text {STC }}$ is the power output of the PV panel at Standard Test Conditions (STC), $G_{\text {STC }}$ is the irradiation at STC, typically $1000 \mathrm{~W} / \mathrm{m}^{2}, \eta_{\text {rel }}$ is the instantaneous relative efficiency, $\eta_{\text {sys }}$ is the system efficiency, and $G^{\prime}, T^{\prime}$ is the irradiance and temperature normalised to STC values according to

$$
\begin{aligned}
G^{\prime} & =\frac{G_{t}}{G_{\mathrm{STC}}}, \\
T^{\prime} & =T_{\bmod }-T_{\bmod _{\mathrm{STC}}} .
\end{aligned}
$$

Parameter $\eta_{\text {rel }}$ normalises the efficiency of the PV panel, which is measured under STC, to the instantaneous values of irradiance and temperature, taking the temperature dependence of the PV panel into account. This instantaneous relative efficiency is given by

$$
\begin{aligned}
\eta_{\text {rel }}\left(G^{\prime}, T^{\prime}\right)= & 1+k_{1} \cdot \ln G^{\prime}+k_{2} \cdot\left(\ln G^{\prime}\right)^{2}+T^{\prime} \\
& \cdot\left(k_{3}+k_{4} \cdot \ln G^{\prime}+k_{5} \cdot\left(\ln G^{\prime}\right)^{2}\right) \\
& +k_{6} \cdot T^{\prime 2} .
\end{aligned}
$$

The coefficients $k_{1}$ to $k_{6}$ are determined empirically. [17] describes measurements taken from 16 different crystalline silicon ( $\mathrm{c}-\mathrm{Si}$ ) modules at the JRC Ispra test site in Italy. These will be used in this paper.

Module temperature $T_{\text {mod }}$ can be estimated from the ambient temperature $T_{\text {amb }}$ and $G_{t}$ by

$$
T_{\mathrm{mod}}=T_{\mathrm{amb}}+c_{t} \cdot G_{t}
$$

Parameter $c_{t}$ describes the self-heating of the module by the incident irradiation and is determined by the mounting system of the PV panel. Roof integrated systems heat up faster $\left(c_{t}=0.056^{\circ} \mathrm{Cm}^{2} / \mathrm{W}\right)$ than free-standing installations $\left(c_{t}=0.02^{\circ} \mathrm{Cm}^{2} / \mathrm{W}\right)[18]$.

Wind speed and wind direction are not included in the calculation of $T_{\text {mod }}$, as it is generally accepted that this makes calculations overly complex without significantly improving model accuracy [16].

Finally, $\eta_{\text {sys }}$ describes additional system losses such as nameplate deviation (-5\%), module mismatch (-1.5\%), ohmic cable losses $(-1.5 \%)$, and soiling $(-1 \%)$, confirming to operational experience by both the authors of this article and [18]. In this article, these losses are assumed static. Also, the PV modules are assumed to be used with a continuous Maximum Power Point Tracking (MPPT) inverter.

The Royal Meteorological Institute (RMI) of Belgium provided us with a dataset containing three years' worth of 10 min averages of parameters $G_{h}, G_{d h}, \theta_{z}$, and $\gamma_{s}$, as well as $T_{\mathrm{amb}}$, as measured on a central location in Flanders.

2.3. PV Inverter Model. PV inverters combine two complex power-electronic stages into one device which is placed between the PV panels and the main grid. The first stage traditionally consists of a dc-dc boost converter which controls the voltage applied to the PV panels so that they operate on or near their Maximum Power Point (MPP). The second stage is a switch-mode inverter that transforms the direct current generated by the PV panels into alternating current suitable for injection in the main grid, normally at unity power factor (PF). The combined efficiency is calculated as

$$
\eta_{\text {inv }}=\frac{P_{\mathrm{AC}}}{P_{\mathrm{DC}}}
$$

with $P_{\mathrm{AC}}$ the power that is injected into the grid

$$
P_{\mathrm{AC}}=P_{\mathrm{DC}}-P_{\text {loss }}
$$

The power losses $P_{\text {loss }}$ in an inverter consist of both a static and a dynamic part. The static part is essentially the power consumed by the control logic and auxiliaries such as communication (Ethernet, display, ...). The dynamic part consists of 
the losses over the semiconductor switches, magnetic components, and wiring and capacitor losses, which are dependent on the current and thus power flowing through them.

In datasheets and literature, the Euro-efficiency value is often conveniently used as an approximation of the total inverter losses of a traditional installation used in Europe [19]. This is described as

$$
\begin{aligned}
\eta_{\text {eur }}= & 0.03 \cdot \eta_{5 \%}+0.06 \cdot \eta_{10 \%}+0.13 \cdot \eta_{20 \%} \\
& +0.10 \cdot \eta_{30 \%}+0.48 \cdot \eta_{50 \%}+0.2 \cdot \eta_{100 \%} .
\end{aligned}
$$

This assumes that the inverter will work for $20 \%$ of the time at maximum power, $48 \%$ of the time at half of its maximum power, etc. In this article, we evaluate the power output of a PV system however at different angles and azimuths, possibly leading to vastly different power regimes imposed on the inverter than in the traditional case. In [20], a simple mathematical model that describes the efficiency curve of any solar inverter under variable load is presented:

$$
\begin{aligned}
\eta\left(P_{\mathrm{DC}, p u}\right) & =A+B \cdot P_{\mathrm{DC}, p u}+\frac{C}{P_{\mathrm{DC}, p u}}, \\
P_{\mathrm{DC}, p u} & =\frac{P_{\mathrm{DC}}}{P_{\mathrm{inv}}},
\end{aligned}
$$

with $P_{\text {inv }}$ being the rated power of the inverter and the coefficients $\mathrm{A}, \mathrm{B}$, and $\mathrm{C}$ being the parameters that represent the efficiency of the inverter at certain points along the inverter efficiency curve. The authors of [20] suggest taking the efficiencies at, respectively, $P_{\mathrm{DC}, p u}=0.1,0.2$, and 1 because these represent the bending points and end point in the efficiency curve of a typical PV inverter. With $\eta_{(P d c, p u)}$ at these points known from the datasheet, solving a system of linear equations yields parameters $\mathrm{A}, \mathrm{B}$, and $\mathrm{C}$. These can then be used to calculate the inverter efficiency under each occurring load. In this article, we also added an additional static loss of $-1.5 \%$ due to nameplate deviation of the inverter.

2.4. Grid Model. The combined PV and inverter model discussed in paragraphs 1 and 2 allow us to simulate realistic AC energy production profiles for any arbitrary orientation of the PV system, based on the RMI provided solar measurements. In this paragraph, we apply this model and input data to a realistic LV feeder network to investigate the impact of different orientations on the power quality and efficiency of the grid.

The LV feeder network model used in this paper is provided by Slovenian DSO Elektro Gorenjska [21]. It consists of a complex three-phase system of 10 subfeeders and 78 nodes. The single line diagram of the grid is depicted in Figure 2. The length of the feeder sections between nodes varies from 10 to $176 \mathrm{~m}$, with a cross-section ranging from 16 to $150 \mathrm{~mm}^{2}$. The MV/LV transformer is of a Dyn 5 type and has a nominal power of $250 \mathrm{kVA}$ and short circuit voltage of $4 \%$ while the no load losses are $325 \mathrm{~W}$ and on-load losses are
$3,250 \mathrm{~W}$, respectively. The primary and secondary nominal voltages are $20 \mathrm{kV}$ and $0.4 \mathrm{kV}$, respectively. The voltages at the secondary side are set to be 1.05 p.u. which is a typical setting used by the DSO in order to avoid undervoltages to the most distant customers when high loading conditions are present. The three-phase short circuit power at the slack bus is $100 \mathrm{MVA}$.

This feeder configuration was selected because it represents a typical European residential, rural feeder.

The dots on the line diagram represent the nodes that have been added with DRES. There are 6 three-phase DRES marked by using a black dot, with the red dots marking the single-phase connected DRES. All data about the phase connection and rated power are listed in Table 1 . The singlephase connected DRES have a rated power between 2 and $5 \mathrm{kWp}$, typical for a residential installation.

All three-phase DRES are already present in the existing LV grid model. The single-phase DRES were added additional. Their placement is done rather uniformly throughout the feeder so that no additional voltage unbalance is introduced by DRES. To examine the influence of the tilting, the optimum angle of $35^{\circ}$ is chosen as a starting point. Then, the peak power of the single-phase DRES is increased up to point where overvoltage occurs in the feeders. This data is then used as input data for all 63 orientations.

The load consumption profiles are also of a residential type, generated by the technique proposed in [22]. In this article, all loads are assumed to have $P F=0.9$. All loads are $15 \mathrm{~min}$ based, and the sum of the apparent power of all loads is depicted in Figure 3. The load profiles are generated for one year which gives in total 35,136 values.

The open-source OpenDSS software is used as a simulation tool. OpenDSS, developed and distributed by the Electric Power Research Institute (EPRI) [23], is a comprehensive and flexible tool for thoroughly simulating electrical networks [24]. The simulation method used in this article is adapted from [25].

The examined period is one year, taking seasonal variations in both PV production and consumption pattern into account. Both are on a 15 min basis, yielding 35,136 simulation steps per simulated PV orientation. In total, 63 orientations are simulated, divided in 9 batches of 7 simulations. In each batch, the azimuth is varied from $-90^{\circ}$ to $+90^{\circ}$ in steps of $30^{\circ}$, with $0^{\circ}$ being the geographical south, while the tilt angle is kept constant. The tilt angle starts at $0^{\circ}$ (horizontal) for the first batch and is increased by $11.5^{\circ}$ for each batch until $80.5^{\circ}$ is reached. The final batch is simulated at a tilt angle of $90^{\circ}$ to avoid self-shadowing effects.

In the considered LV grid, the penetration of RES is rather high. During high production and low loading periods, the distribution grids with high penetration of renewable energy sources may experience overvoltages at some farther points from the MV/LV distribution transformer. In order to prevent power quality problems such as overvoltages, the DRES are disconnected from the grid for a certain time period.

The goal of the simulation is to investigate how the different PV orientations influence

(i) the total PV production 


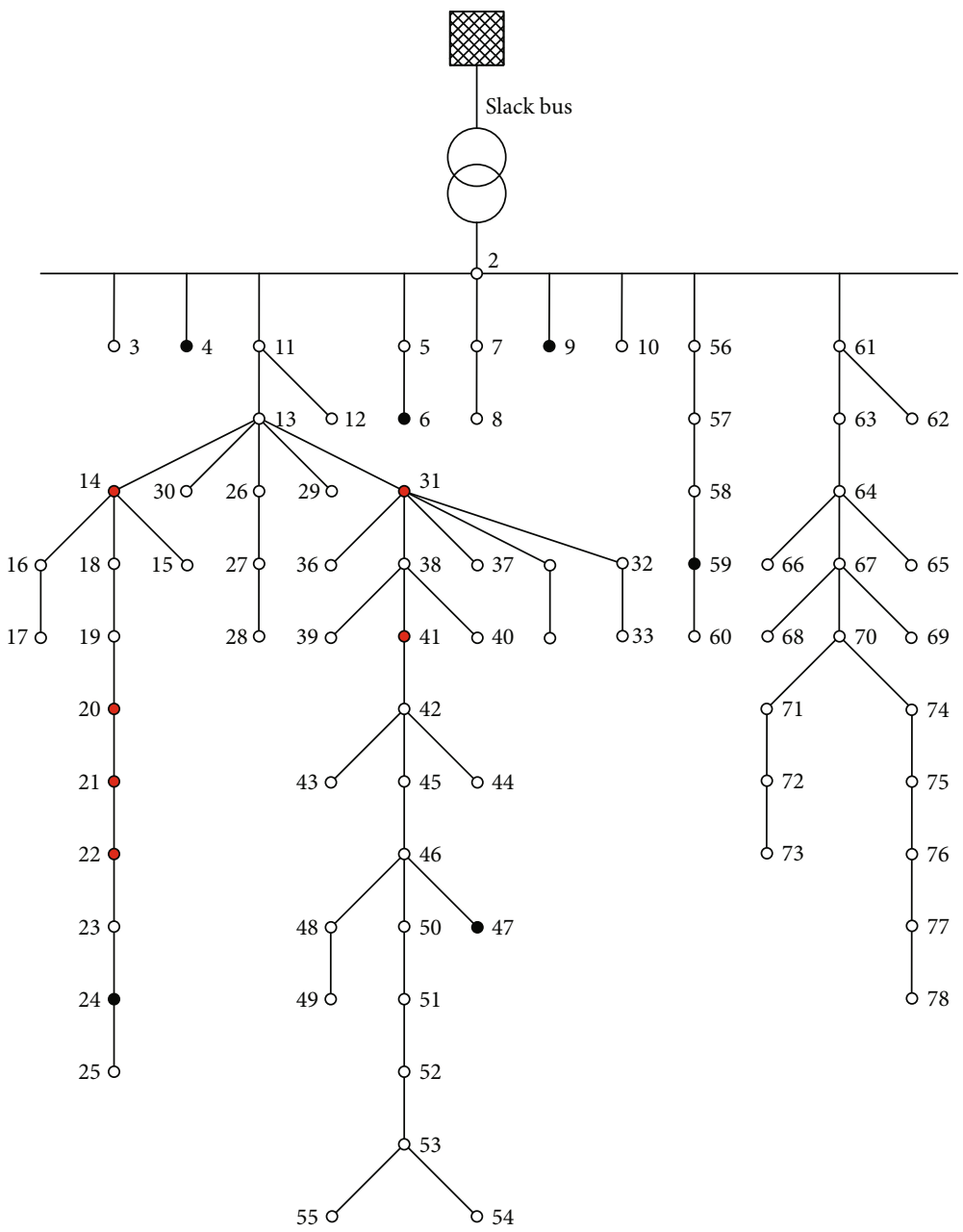

Figure 2: Single line diagram of the examined LV grid.

TABLE 1: Overview of DRES-equipped nodes.

\begin{tabular}{|c|c|c|c|c|c|}
\hline \multicolumn{3}{|c|}{ Three-phase connected DRES } & \multicolumn{3}{|c|}{ Single-phase connected DRES } \\
\hline DRES & $\begin{array}{c}\text { Rated } \\
\text { power } \\
\text { kW }\end{array}$ & Connection & DRES & $\begin{array}{c}\text { Rated } \\
\text { power } \\
\mathrm{kW}\end{array}$ & Connection \\
\hline $\mathrm{DRES}_{4}$ & 21.75 & $\mathrm{abc}$ & DRES $_{14}$ & 1.5 & c \\
\hline DRES $_{6}$ & 51.7 & $\mathrm{abc}$ & DRES $_{20}$ & 1.5 & b \\
\hline $\mathrm{DRES}_{9}$ & 52.5 & $a b c$ & DRES $_{21}$ & 1.5 & c \\
\hline DRES $_{24}$ & 15 & $\mathrm{abc}$ & DRES $_{22}$ & 1.5 & a \\
\hline DRES $_{47}$ & 45 & $\mathrm{abc}$ & DRES $_{31}$ & 1.5 & $\mathrm{a}$ \\
\hline DRES $_{59}$ & 22.5 & $\mathrm{abc}$ & $\mathrm{DRES}_{41}$ & 1.5 & c \\
\hline
\end{tabular}

(ii) the amount of PV production curtailed by overvoltage conditions

(iii) the amount of PV production injected into the grid because of mismatch between PV production and load consumption profiles

(iv) the influence of the PV orientation on the power quality of the grid
The simulation is performed with time series, and the corresponding values of the vectors of the solar irradiation and the load profiles are simulated for each time step. Suppose that at some point nodes 22 to 24 experience overvoltages, then DRES 22 and 24 will be turned off immediately for that time step and the simulation will move to the next step. Because of the discretisation of the dataset in $15 \mathrm{~min}$ intervals, this will however result in a large power curtailment, which may not happen in reality. In practice, RES 24 will turn off before RES 22 which might be sufficient to prevent the overvoltages and it may not be necessary to turn off RES 22. In order to overcome this disadvantage of the time series simulations and prevent false overvoltage tripping, an internal loop is introduced. This internal loop is accessed only if an overvoltage problem occurs. In this loop, the set power is increased gradually with a step of $5 \%$ of the nominal to the maximum set point which will trip the DRES one by one in case of overvoltages and not all at once.

\section{Simulation Results}

3.1. PV System Model Evaluation. To evaluate the performance of the presented PV system model, we simulate two 


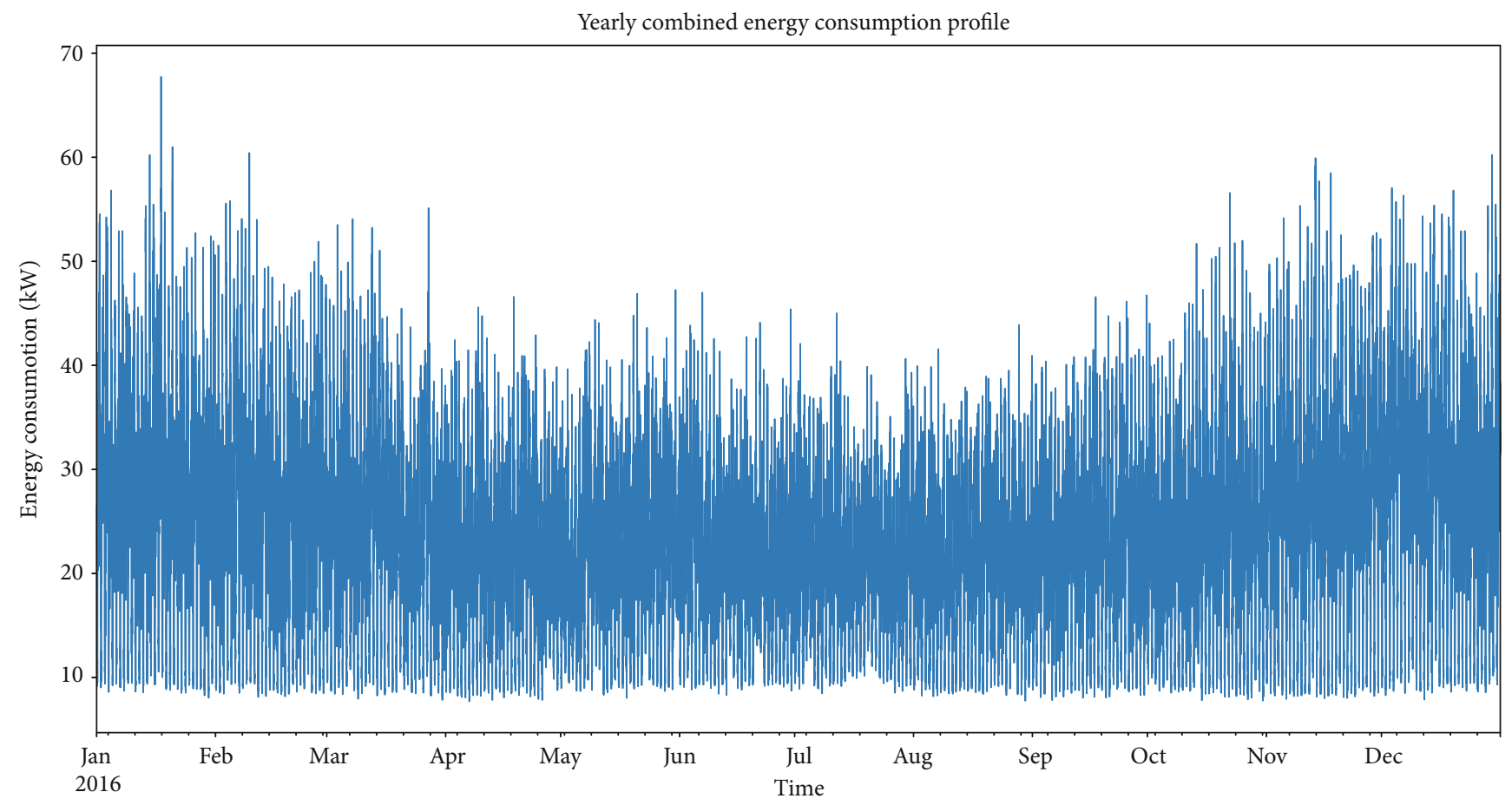

FIGURE 3: Combined load profiles for all nodes on the feeder.

TABle 2: Comparison of measured and simulated PV output.

\begin{tabular}{lllllr}
\hline & \multicolumn{2}{c}{ PV system A } & \multicolumn{2}{c}{ PV system B } & \multicolumn{2}{c}{ PVWatts } \\
& Measured & Simulated & Measured & Simulated & Measured $^{\text {Simulated }}$ \\
\hline 2014 & $2,434 \mathrm{kWh}$ & $2,414 \mathrm{kWh}$ & $4,414 \mathrm{kWh}$ & $4,381 \mathrm{kWh}$ & - \\
2015 & $2,512 \mathrm{kWh}$ & $2,484 \mathrm{kWh}$ & $4,592 \mathrm{kWh}$ & $4,508 \mathrm{kWh}$ & - \\
2016 & $2,454 \mathrm{kWh}$ & $2,414 \mathrm{kWh}$ & $4,470 \mathrm{kWh}$ & $4,425 \mathrm{kWh}$ & - \\
Average & $2,467 \mathrm{kWh}$ & $2,438 \mathrm{kWh}$ & $4,492 \mathrm{kWh}$ & $4,438 \mathrm{kWh}$ & - \\
\hline
\end{tabular}

* Simulated measurement.

existing PV systems of which we have access to the specifications and yearly energy production during the same years contained in the provided solar irradiation dataset. The PV systems were selected because they were free standing and free of (self) shadowing effects. The results are presented in Table 2. Further specifications are provided in Table 3 addendum.

We also include the result simulated for the reference system by the NREL PVWatts Calculator [26], an online PV system simulation tool developed by the US National Renewable Energy Laboratory. This free and easy to use simulator accepts many of the same parameters used in this model (e.g., nameplate deviation, module mismatch, and inverter efficiency) and is also based on ground-based irradiation measurements. According to its technical manual [27], the irradiation model is based on the Perez 1990 algorithm [28] but with the modification that diffuse irradiation is treated as isotropic for solar angles between $87.5^{\circ}$ and $90^{\circ}$. It uses irradiation data with hourly values, while the model presented in this paper offers more granularity by using 15minute-based data. Other differences include taking the effects of wind speeds on solar module cooling into account, as well as the light-induced degradation (LID) phenomenon. LID is the additional long-term degradation of solar cell performance when exposed to light, especially pronounced in monocrystalline solar cells [29]. Because it varies wildly with the quality of the solar cell silicon, we choose not to model this behaviour in the presented model.

The comparison with the measured PV output shows that the PV system model presented in this paper performs accurately. The relative error is $1.18 \%$ and $1.2 \%$ for outputs $\mathrm{A}$ and $\mathrm{B}$, respectively, and $1.77 \%$ compared to the output of PVWatts. In all cases, the model results are slightly more conservative. Note that the PVWatts tool only simulates for a standard solar year, not for an arbitrarily chosen year.

While a detailed evaluation of the model performance falls out of the scope of this paper, we believe that comparing the model output with yearly outputs of real PV installations provides a sufficient indication of the model performance. Because the yearly output consists of the summation of the 15-minute simulation intervals, deviations in each simulation step will be summed as well and should have a rather large influence the total yearly result. Because this is not the case, we can conclude that the simulation model performs adequately. 
TABLE 3: Addendum.

\begin{tabular}{lcc}
\hline PV system parameters & PV system A & PV system B \\
\hline Installed DC power & $2.6 \mathrm{~kW}$ & $4.7 \mathrm{~kW}$ \\
Inverter AC power & $2.6 \mathrm{~kW}$ & $5 \mathrm{~kW}$ \\
Type & Free standing & Rooftop, free standing \\
Longitude & 51.011556 & 51.012364 \\
Latitude & 3.708222 & 3.710860 \\
Azimuth & $0^{\circ}$ & $0^{\circ}$ \\
Tilt angle & $35^{\circ}$ & $23^{\circ}$ \\
\hline
\end{tabular}

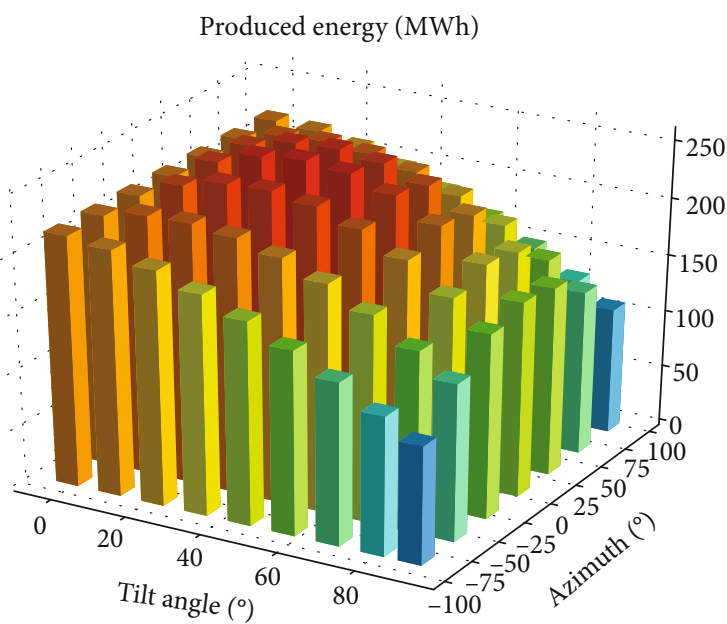

FIgURE 4: Yearly combined PV output for all tilt and azimuth angles.

3.2. Total PV Production. Figure 4 displays the total PV production. This is the yearly output energy of all PV systems in the simulated feeder combined. The [34.5:0] ([tilt angle : azimuth]) simulation yields the greatest output of $256 \mathrm{MWh}$ per year, while [90:-90] and [90:90] score 110 MWh and $105 \mathrm{MWh}$, respectively. This is to be expected, since the optimal orientation of a PV system at the latitude of Belgium is considered to be $[35: 0]$. Full numerical results can be found in Table 4.

Notice that lowering the tilt angle of the PV panels in general only slightly decreases the output of the PV system, while increasing the tilt angle leads to rapidly dropping yields once the optimal orientation has been passed. This again is due to the specific geographical coordinates of Belgium and will change with different latitudes. It also shows that deviating from the optimal angles can have a severe effect on PV yield. For example, deviating from $[34.5: 0]$ to $[11.5:-30]$ leads to a drop in yearly production output of $7.6 \%$.

3.3. Curtailed PV Production. Figure 5 displays the amount of curtailed PV production. This quantifies the total amount of $\mathrm{PV}$ production that is curtailed, and thus lost, across the feeder due to overvoltage conditions experienced by the solar inverters. In other words, it is the additional energy that could have been generated if no overvoltages were to happen. If the inverter experiences an overvoltage condition, it disconnects from the grid until the overvoltage condition has ended.
TABLE 4: Yearly combined PV output for all tilt and azimuth angles.

\begin{tabular}{lccccccc}
\hline \multirow{2}{*}{ Output (MWh) } & -90 & -60 & -30 & 0 & 30 & 60 & 90 \\
\hline Tilt angle & & & & & & & \\
0 & 220.5 & 220.5 & 220.5 & 220.5 & 220.5 & 220.5 & 220.5 \\
11.5 & 216.1 & 227.8 & 236.5 & 240.1 & 237.5 & 229.5 & 218.1 \\
23 & 206.7 & 228.8 & 245.2 & 251.9 & 247.1 & 232.0 & 210.5 \\
34.5 & 194.3 & 224.5 & 246.8 & 256.0 & 249.2 & 228.7 & 199.5 \\
46 & 179.7 & 215.2 & 241.5 & 252.4 & 244.4 & 220.3 & 186.1 \\
57.5 & 163.0 & 201.4 & 229.6 & 241.3 & 232.9 & 207.0 & 170.1 \\
69 & 144.3 & 183.0 & 211.4 & 223.0 & 214.9 & 188.8 & 151.4 \\
80.5 & 123.6 & 160.5 & 187.1 & 197.7 & 190.6 & 166.1 & 130.1 \\
90 & 105.2 & 139.2 & 163.0 & 171.7 & 166.1 & 144.2 & 110.7 \\
\hline
\end{tabular}

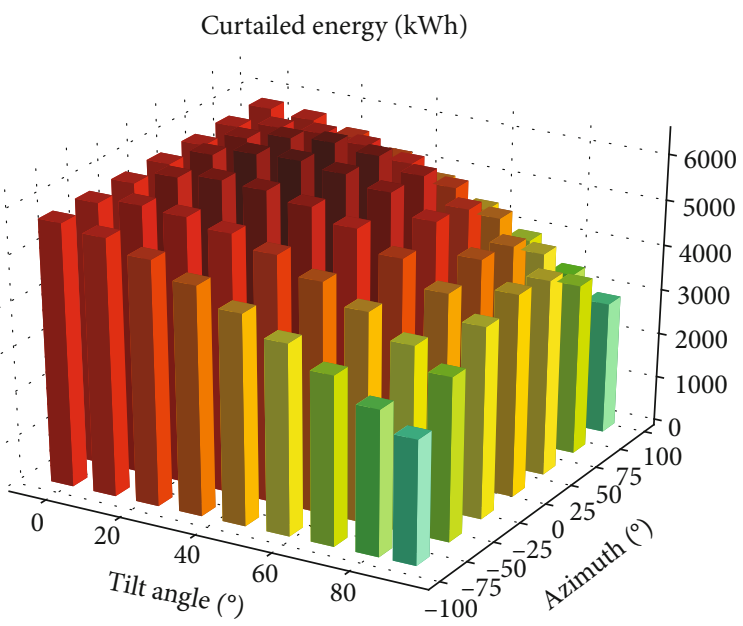

FIGURE 5: Yearly curtailed PV output for all tilt and azimuth angles.

The profile of curtailed PV energy is similar to that of the produced PV energy. Indeed, as PV production is increased, so do the chances of overvoltage conditions increase because the grid has to absorb more PV production, leading to a voltage rise. Table 5 contains a numerical overview of the curtailed PV production for each orientation.

The maximum PV production curtailed is again at the [34.5:0] orientation, where $6.4 \mathrm{MWh}$ of production is lost. The least PV production is lost at the [90:90] orientation, where $2.9 \mathrm{MWh}$ of production is curtailed.

\subsection{Grid Power Quality Conditions}

3.4.1. Feeder Losses. Feeder losses is energy loss through the feeder cables. In our simulation, this is calculated internally by the OpenDSS software. In LV feeders such as the one considered, the main contribution is due to ohmic losses which are proportional with the line resistance $R$ and squared with the amount of current $I$ flowing through the cables.

$$
P_{\text {loss }}=I^{2} \cdot R
$$

In grids with DRES, losses occur both due to the "inward" flow of energy, from transformer to load, as due to the inner 
TABLE 5: Yearly curtailed PV output for all tilt and azimuth angles.

\begin{tabular}{lccccccc}
\hline $\begin{array}{l}\text { Curtailment } \\
(\mathrm{kWh})\end{array}$ & -90 & -60 & -30 & 0 & 30 & 60 & 90 \\
\hline $\begin{array}{l}\text { Tilt angle } \\
0\end{array}$ & 5,838 & 5,838 & 5,838 & 5,838 & 5,838 & 5,838 & 5,838 \\
11.5 & 5,716 & 5,970 & 6,149 & 6,222 & 6,168 & 5,994 & 5,760 \\
23 & 5,447 & 5,918 & 6,273 & 6,414 & 6,352 & 6,039 & 5,541 \\
34.5 & 5,098 & 5,758 & 6,242 & 6,454 & 6,430 & 5,961 & 5,264 \\
46 & 4,703 & 5,503 & 6,086 & 6,357 & 6,333 & 5,754 & 4,911 \\
57.5 & 4,270 & 5,128 & 5,816 & 6,154 & 6,085 & 5,406 & 4,497 \\
69 & 3,795 & 4,687 & 5,369 & 5,717 & 5,552 & 4,926 & 4,002 \\
80.5 & 3,274 & 4,167 & 4,821 & 5,097 & 4,942 & 4,335 & 3,428 \\
90 & 2,805 & 3,666 & 4,274 & 4,510 & 4,358 & 3,793 & 2,933 \\
\hline
\end{tabular}

flow of energy from DRES to local loads. In general, the total feeder losses in grids with DRES can be lower than in grids without DRES because of the local consumption of energy, but if production and consumption profile are severely mismatched, this could lead to higher losses.

Figure 6 represents the feeder losses for the different orientations relative to the feeder losses if no DRES were present in the feeder. This last value was calculated in an additional simulation run with all PV systems removed from the feeder, leading to a no-PV feeder loss of $4,238 \mathrm{kWh}$. This was taken as a reference value to plot the feeder losses with PV systems present. Table 6 contains the numerical results for the absolute yearly feeder losses for each orientation.

The pattern is again clear, with significantly higher losses around the optimal orientation angles. The relative difference between the separate orientations is however most pronounced here, with the optimal orientation $[34.5: 0]$ leading to $1,225 \mathrm{kWh}$ additional losses compared to the no-PV reference scenario, and the extreme [90:90] orientation only leading to $334 \mathrm{kWh}$ of additional losses.

Note that even for the best case of [34.5:0], highlighted in bold, adding DRES to the feeder still yields an increase of the losses of $1,559 \mathrm{kWh}$ to the reference, no-DRES result of $4,238 \mathrm{kWh}$.

3.4.2. Feeder Losses Relative to PV Production. Although the results until now have indicated a clear trend, it is interesting to note that the feeder losses have a significantly different profile at low tilt angles than the PV production output. While the latter only drops a rather small amount of power at low tilt angles, even across different azimuth angles, the former has a more pronounced decrease in losses. Table 7 lists the PV output reduction reduced by the gains in feeder losses, both compared to the optimal case of [34.5:0].

Figure 7 displays a visual plot of the results of Table 7. This indicates that the optimal balance between reducing feeder losses while minimising the impact on PV output is attained by decreasing the tilt angle of the PV panels. While still a significant total yearly loss of around $34 \mathrm{MWh}$, the impact of increasing the tilt angle on the combined result is much more drastic. At high tilt angles, the decrease in PV output has a

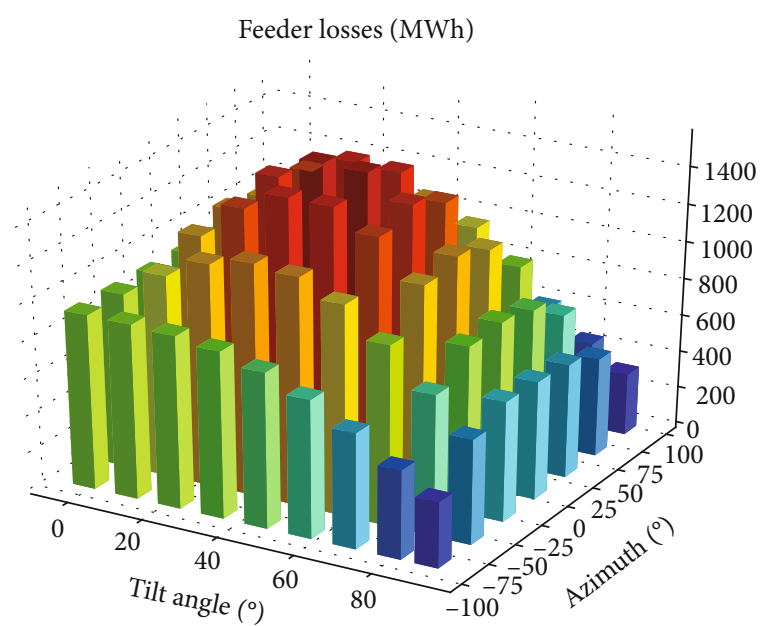

FIgURE 6: Yearly relative feeder losses for all tilt and azimuth angles.

TABLE 6: Yearly absolute feeder losses for all tilt and azimuth angles.

\begin{tabular}{lccccccc}
\hline $\begin{array}{l}\text { Feeder losses } \\
(\mathrm{kWh})\end{array}$ & -90 & -60 & -30 & 0 & 30 & 60 & 90 \\
\hline Tilt angle & & & & & & & \\
0 & 5,183 & 5,183 & 5,183 & 5,183 & 5,183 & 5,183 & 5,183 \\
11.5 & 5,182 & 5,327 & 5,431 & 5,467 & 5,428 & 5,323 & 5,179 \\
23 & 5,171 & 5,437 & 5,621 & 5,682 & 5,611 & 5,426 & 5,167 \\
34.5 & 5,140 & 5,487 & 5,723 & 5,797 & 5,703 & 5,470 & 5,136 \\
46 & 5,080 & 5,466 & 5,721 & 5,795 & 5,694 & 5,444 & 5,074 \\
57.5 & 4,988 & 5,372 & 5,612 & 5,674 & 5,581 & 5,346 & 4,978 \\
69 & 4,865 & 5,211 & 5,412 & 5,452 & 5,380 & 5,182 & 4,849 \\
80.5 & 4,721 & 5,000 & 5,140 & 5,153 & 5,107 & 4,968 & 4,700 \\
90 & 4,597 & 4,807 & 4,889 & 4,878 & 4,855 & 4,772 & 4,572 \\
\hline
\end{tabular}

much larger impact than the drop in feeder losses, especially if the azimuth angles are increased east or westwards.

3.4.3. Voltage Unbalance. Next to overvoltage conditions, grids with DRES can experience increased voltage unbalance between the phases. This is caused by single-phase loads and generators, such as PV inverters, not evenly distributed between phases increasing the mismatch between production and consumption profiles. In combination with the overvoltage issues along the feeder, this voltage unbalance further decreases the grid reception capacity for DRES [30]. The amount of voltage unbalance in residential grids is expected to become much worse in the future due to the increasing number of single-phase DRES and large single-phase loads such as electric vehicles and heat pumps.

For the results, we only consider the zero-sequence $\mathrm{VUF}_{0}$ (voltage unbalance factor) and negative-sequence $\mathrm{VUF}_{2}$. $\mathrm{VUF}_{2}$ is calculated as follows, with $V_{1}$ and $V_{2}$ being the positive-sequence and negative-sequence voltages in absolute values, respectively.

$$
\mathrm{VUF}_{2}=\frac{V_{2}}{V_{1}} \cdot 100 \%
$$


TABLE 7: Combined feeder and PV production losses relative to the optimal case.

\begin{tabular}{|c|c|c|c|c|c|c|c|}
\hline \multirow{2}{*}{ Combined losses (kWh) } & \multicolumn{7}{|c|}{ Azimuth } \\
\hline & -90 & -60 & -30 & 0 & 30 & 60 & 90 \\
\hline \multicolumn{8}{|l|}{ Tilt angle } \\
\hline 0 & -34.886 & -34.886 & -34.886 & -34.886 & -34.886 & -34.886 & -34.886 \\
\hline 11.5 & -39.285 & -27.730 & -19.134 & -15.570 & -18.131 & -26.026 & -37.282 \\
\hline 23 & -48.674 & -26.840 & -10.624 & -3.985 & -8.714 & -23.629 & -44.870 \\
\hline 34.5 & -61.043 & -31.190 & -9.126 & 0.0 & -6.706 & -26.973 & -55.839 \\
\hline 46 & -75.583 & -40.469 & -14.424 & -3.598 & -11.497 & -35.347 & -69.177 \\
\hline 57.5 & -92.191 & -54.175 & -26.215 & -14.577 & -22.884 & -48.549 & -85.081 \\
\hline 69 & -110.768 & -72.414 & -44.215 & -32.655 & -40.683 & -66.585 & -103.652 \\
\hline 80.5 & -131.324 & -94.703 & -68.243 & -57.656 & -64.710 & -89.071 & -124.803 \\
\hline 90 & -149.600 & -115.810 & -92.092 & -83.381 & -88.958 & -110.775 & -144.075 \\
\hline
\end{tabular}

Combined feeder \& PV losses (MWh)

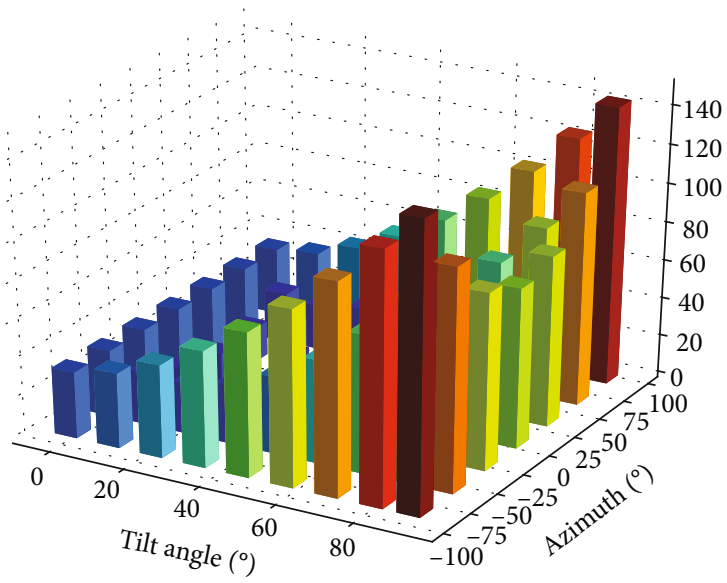

FIGURE 7: Combined feeder and PV production losses relative to the optimal case.

The negative-sequence voltage arises due to the existence of negative-sequence currents. A perfectly balanced threephase system only generates positive-sequence currents. If an unbalance is introduced, negative-sequence currents are also generated. This is harmful for rotating induction machines, because the negative-sequence current generates a torque ripple at twice the grid frequency, leading to additional heating and vibration and shortening the lifespan of the machine. Therefore, EN50160 [31] limits $\mathrm{VUF}_{2}$ to $2 \%$.

Similar to $\mathrm{VUF}_{2}, \mathrm{VUF}_{0}$ is calculated by replacing $V_{2}$ with the zero-sequence voltage $V_{0}$ created by the introduction of zero-sequence currents.

$$
\mathrm{VUF}_{0}=\frac{V_{0}}{V_{1}} \cdot 100 \%
$$

Zero-sequence currents are another result of phase unbalance, causing this current to flow through the neutral conductor. While EN5016 does not impose limits to $\mathrm{VUF}_{0}$, it is still important to keep this value to a minimum.
Increased current flow through the neutral conductor can cause a neutral point shift, limiting the reception capacity of the grid for additional DRES. It can also cause additional losses in the substation transformer if used in $\Delta-Y$ configuration. Additionally, it is shown in [11,30,32] and [33] that overvoltages can be avoided by mitigating the zerosequence current which results in less curtailed power and allows for an increased penetration of DRES.

Because the VUF changes across the feeder, depending on the loading and injection at each node, the VUF at each node is displayed in a box-and-whisker plot. The outliers are represented by the red markers. We present the results for 9 orientations in Figures 8 .

The effect of changing the orientation of the PV panels on the median of both $\mathrm{VUF}_{0}$ and $\mathrm{VUF}_{2}$ is negligible. There is a slight correlation with increasing optimal orientation, that is, orientations closer to the [34.5:0] profile, as can be expected because of the increasing PV power output at those angles.

There is also a correlation between increasing azimuth and the deviation of the positive outliers. The higher the azimuth angle, the further certain outliers tend to deviate from the upper quartile. This could be explained by the increasing mismatch of PV production on PV systems oriented west, which shift their production peak towards later hours, and the evening peak in the residential load profile. On nodes where a phase mismatch between single-phase PV systems and loads is present, this effect can make the mismatch even more pronounced, leading to higher VUF. However, on nodes where the mismatch is not that severe, VUF should actually be lower due the better matching. This is reflected in the median VUF which indeed stays unchanged.

3.4.4. Voltage Profile. Finally, we investigate the impact of the $\mathrm{PV}$ orientation on the voltage ramp profile for nodes along the most constrained grid segment, which in Figure 2 is the path along node 2-11-13-14 to 25. Changing the orientation of PV panels can displace the effect on the grid voltage through time, with more eastward orientations leading to earlier voltage peaks and, conversely, more southward orientation to a later time. This effect will be most pronounced 

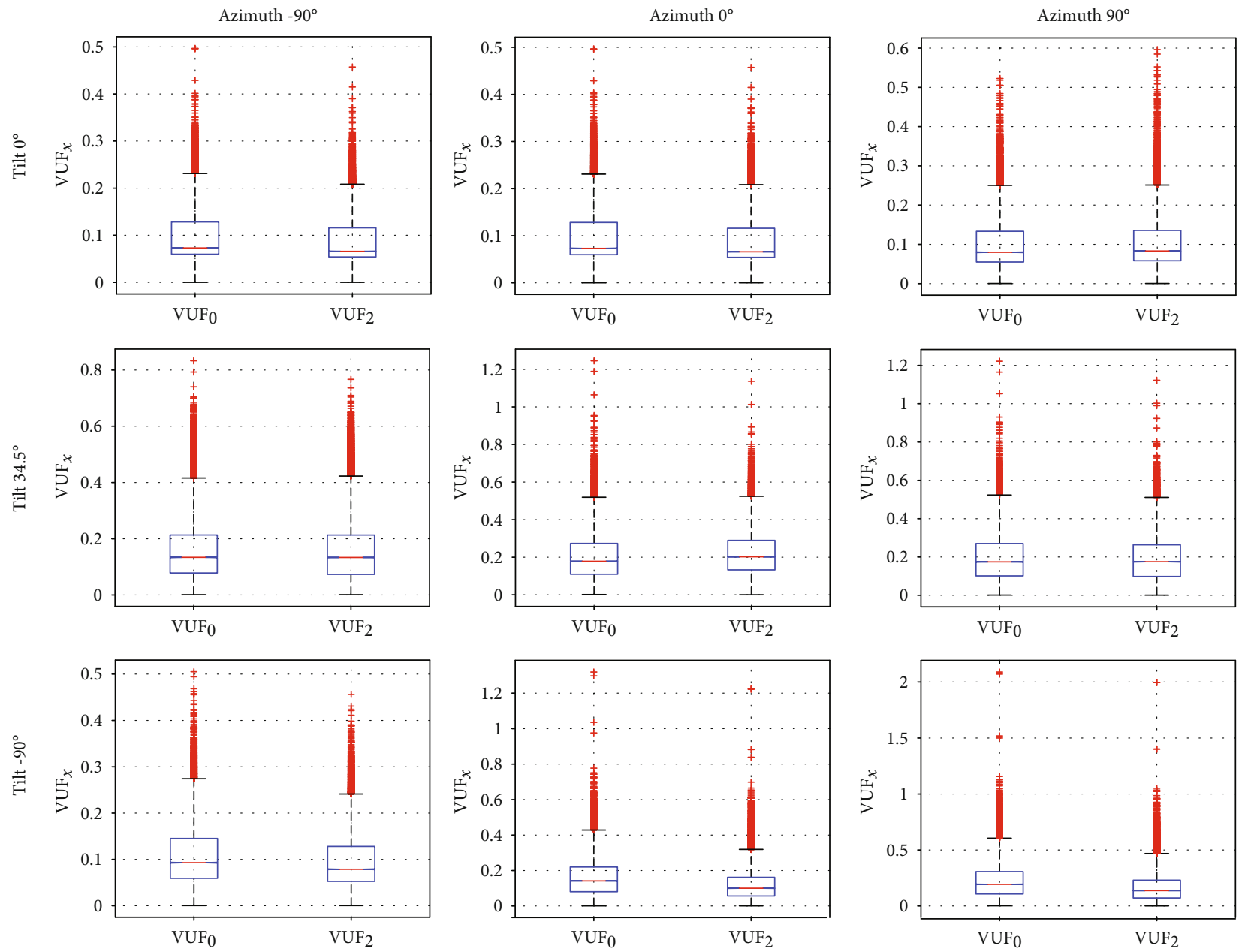

FIGURE 8: Percentual VUFs for 9 selected orientations.

on the grid segment with the largest ratio of PV installations. Additionally, we study the impact for both a cloudy and a sunny day.

Figure 9 displays the average voltage profile of the threephase feeder along the most congested path for three distinct azimuth orientations of $-90^{\circ}$ (east), $0^{\circ}$ (south), and $90^{\circ}$ (west) of the PV panels. To limit the amount of results to be displayed, the tilt angle was kept constant at the optimal $34.5^{\circ}$, at which the impact on grid voltage would be most outspoken. Two days in the same week of June were selected, one cloudy and one sunny.

Shifting the azimuth orientation of the PV panels has a clear impact on the time of day overvoltage conditions arise, and the inverter starts curtailing. In both cloudy and sunny cases, the maximum voltages are reached well before noon in eastward orientation, shifting to noon at southward orientation and settling in the late afternoon for westward orientation. The effect is of course most apparent for nodes further along the feeder because of the reverse voltage drop. The effect will be more superficial for periods outside summer, but due to decreased solar irradiation and increased electrical consumption, the amount of overvoltage conditions decrease significantly as well.

\section{Conclusions and Further Research}

In this article, the effects of different orientations of PV panels on congestion and voltage profile of the local LV grid were examined. We presented a simulation model of a PV system which combined an irradiation model, solar panel model, and inverter model in order to generate time series of PV power output for arbitrarily orientations and installation sizes. Supplied with a meteorological dataset for Belgium, this model was shown to perform adequately when compared to real-life PV production measurements and another, popular PV simulation tool.

The generated PV production profiles were then used as the input for a grid simulation, where we determined the yearly PV output, the curtailed PV energy due to overvoltage conditions in the grid, the grid losses, and the voltage unbalance factors.

It was shown that the optimal orientation for maximising PV output was at azimuth $0^{\circ}$ (facing south) with a tilt angle of $34.5^{\circ}$. This orientation also leads to the highest amount of PV power being curtailed by overvoltage conditions and the highest losses in the distribution grid.

Changing the orientation angles has a noticeable impact on the results. For example, deviating towards an azimuth 
Cloudy day

Voltage profile along feeder (V)

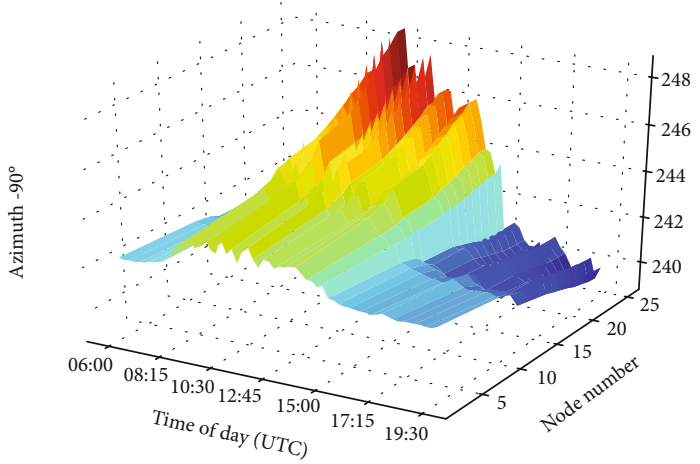

Voltage profile along feeder (V)

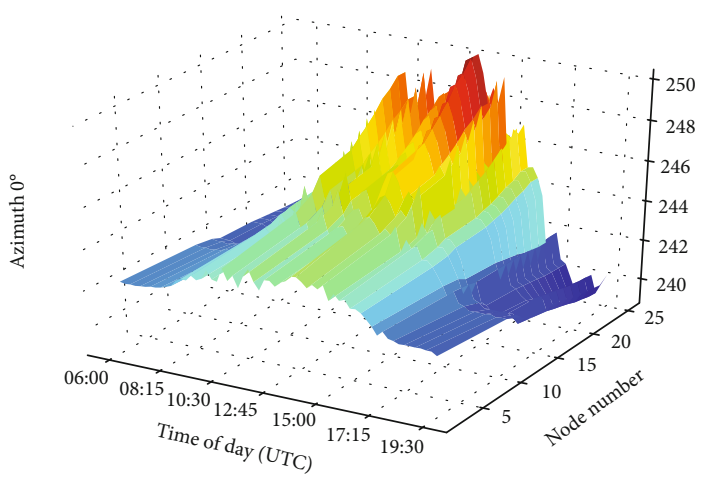

Voltage profile along feeder $(\mathrm{V})$
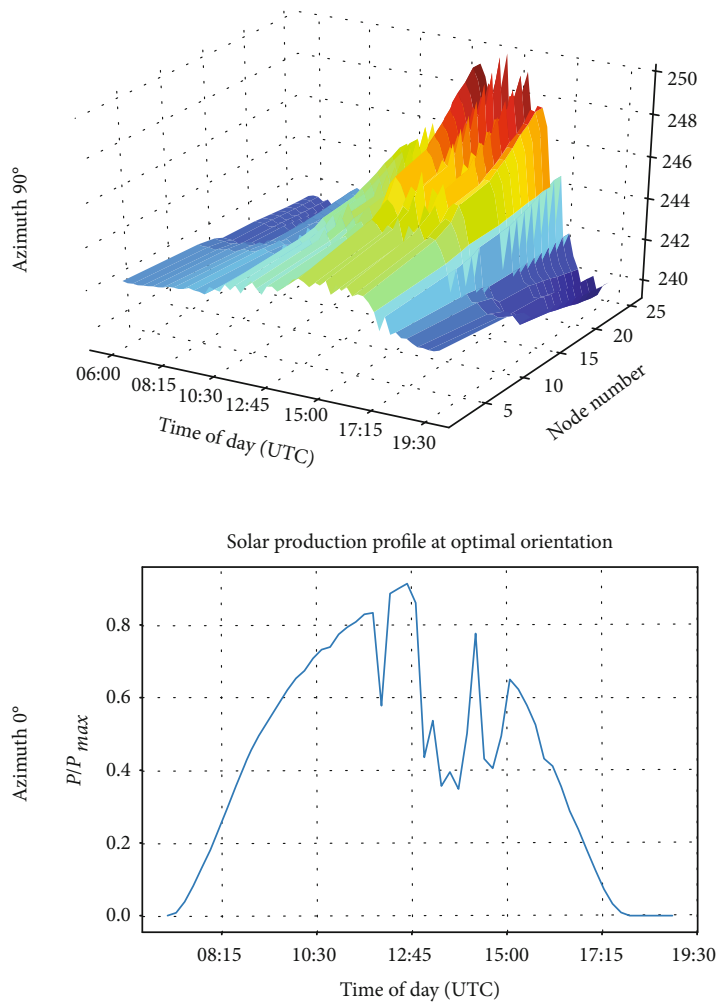

Sunny day

Voltage profile along feeder $(\mathrm{V})$

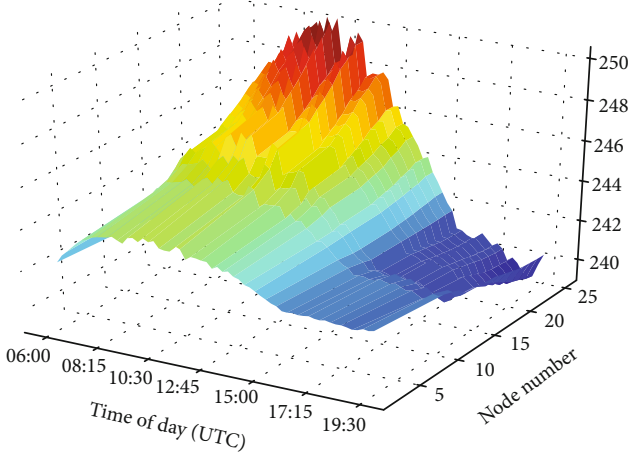

Voltage profile along feeder (V)

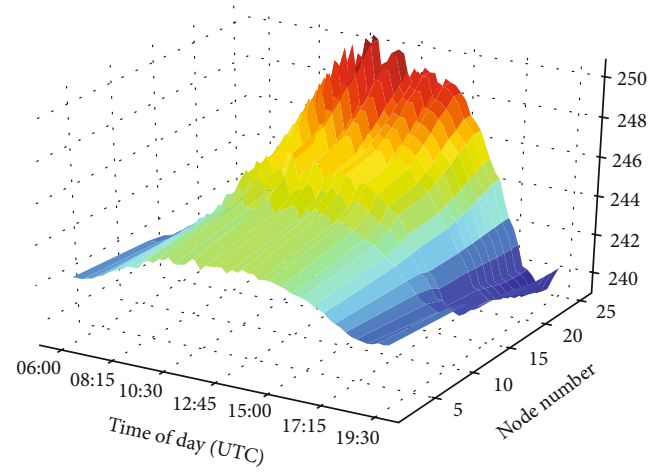

Voltage profile along feeder $(\mathrm{V})$
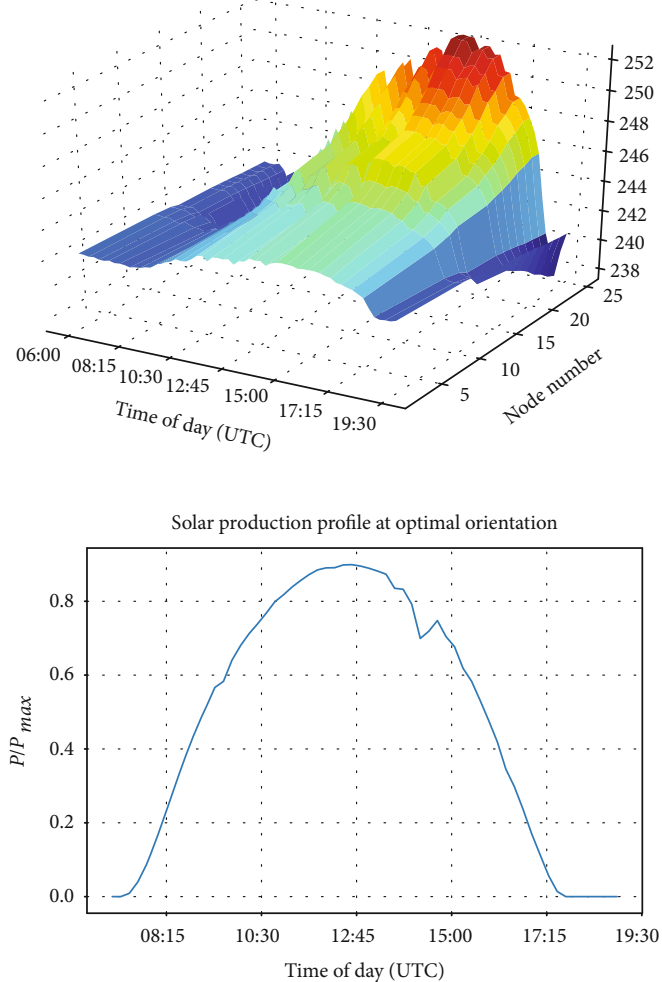

FIgURE 9: Voltage profile along node 2-11-13-14 to 25 for PV panel tilt of $34.5^{\circ}$. 
TABLE 8: Relative systemic loss of energy compared to the optimal orientation.

\begin{tabular}{lccccccc}
\hline \multirow{2}{*}{ Loss of energy (\%) } & -90 & -60 & -30 & 0 & 30 & 60 & 90 \\
\hline Tilt angle & & & & & & & \\
0 & 14.3 & 14.3 & 14.3 & 14.3 & 14.3 & 14.3 & 14.3 \\
11.5 & 16.1 & 11.4 & 7.9 & 6.4 & 7.5 & 10.7 & 15.3 \\
23 & 19.9 & 11.0 & 4.4 & 1.7 & 3.6 & 9.7 & 18.4 \\
34.5 & 24.9 & 12.7 & 3.7 & $\mathbf{0 . 0}$ & 2.7 & 11.0 & 22.8 \\
46 & 30.8 & 16.4 & 5.8 & 1.4 & 4.6 & 14.4 & 28.2 \\
57.5 & 37.5 & 22.0 & 10.6 & 5.9 & 9.3 & 19.7 & 34.6 \\
69 & 45.0 & 29.4 & 18.0 & 13.3 & 16.6 & 27.1 & 42.2 \\
80.5 & 53.4 & 38.5 & 27.8 & 23.6 & 26.4 & 36.3 & 50.8 \\
90 & 60.8 & 47.1 & 37.5 & 34.0 & 36.3 & 45.1 & 58.6 \\
\hline
\end{tabular}

of $-30^{\circ}$ and tilt angle of $11.5^{\circ}$, the energy curtailment drops with $4.7 \%$ resulting in a gain of $305 \mathrm{kWh}$, while grid losses are reduced by $6.3 \%$ or $366 \mathrm{kWh}$. However, total PV output also drops by $19,500 \mathrm{kWh}$ or $7.6 \%$. This means that, while losses due to curtailment of energy and grid losses are reduced, the resulting total PV energy is also reduced because the PV system output decreases significantly faster than the reduction in losses. Table 8 contains the results for each orientation, quantifying the total systemic loss of energy relative to the optimal orientation.

It is clear that when optimising for maximum useable DRES production, changing the orientation of the solar panels away from the optimal angle only leads to more loss of energy because the PV system output drops faster than the gains in curtailment and grid losses.

It is however worth noting that reducing the tilt angle has a more outspoken effect on grid losses while not leading to severe drops in PV power output. For example, decreasing the tilt angle in the optimal case from $34.5^{\circ}$ to $0^{\circ}$ decreases the grid losses with 10.6\%, while the PV production output decreases with $13.7 \%$. In some cases with constrained grids, this might be an acceptable trade-off. Some form of economic compensation mechanism by the DSO will probably be required.

Concerning voltage unbalance, it was shown that the effect of changing orientation of PV panels is negligible. In the performed simulation of a realistic grid, the VUFs were found to be well under the maximum level of $2 \%$, leading to the conclusion that most grids can cope adequately with DRES injection. While in some grid segments, it might be possible that several DRES units inject on the same phase leading to unbalance; in the totality of the grid, these mismatches blend away. There was a small effect of the azimuth angles on the VUF, further strengthening the conclusion that is best to work on tilt angles when trying to reduce grid losses by different solar panel orientations.

It is also noteworthy that different azimuth orientations of the PV panels have a profound effect on the time of day when overvoltage conditions can arise, with eastward orientation shifting clearly towards earlier hours and, conversely, southward orientation towards later hours. This can prove useful for situations where grid congestion must be avoided during certain hours.

With the simulation model presented in this abstract, further possible research can be investigated. The model might be adapted to allow for multiple orientations per PV system, e.g., when an installation is split in an east-facing and westfacing side, a typical occurrence on classical gable roofs.

\section{Data Availability}

The irradiation data used to support the findings of this study were supplied by the Belgian Royal Meteorological Institute under license and so cannot be made freely available. Requests for access to these data should be made through the request form at https://www.meteo.be/en/about-rmi/ contact/contact-rmi/contact-form.

\section{Conflicts of Interest}

The authors declare that they have no conflicts of interest.

\section{Acknowledgments}

The authors would like to thank the Belgian Royal Meteorological Institute for providing the meteorological datasets and Elektro Gorenjska for providing the distribution feeder parameters.

\section{References}

[1] Vlaamse Regulator voor Elektriciteit en gas (VREG), "Aantal zonnepanelen en hun vermogen," June 2017, http://www .vreg.be/sites/default/files/statistieken/aantal_en_ vermogen_-_update_september_16.pdf.

[2] D. Bozalakov, M. J. M. Al-Rubaye, J. I. Laveyne, A. Van den Bossche, and L. Vandevelde, "Voltage unbalance and overvoltage mitigation by using the three-phase damping control strategy in battery storage applications," in 2018 7th International Conference on Renewable Energy Research and Applications (ICRERA), pp. 753-759, Paris, France, October 2018.

[3] M. H. J. Bollen and M. Häger, "Impact of increasing penetration of distributed generation on the number of voltage dips experienced by end-customers," in 18th International Conference and Exhibition on Electricity Distribution (CIRED 2005), Turin, 2005.

[4] L. Degroote, B. Renders, B. Meersman, and L. Vandevelde, "Neutral-point shifting and voltage unbalance due to singlephase DG units in low voltage distribution networks," in 2009 IEEE Bucharest PowerTech, Bucharest, Romania, JuneJuly 2009.

[5] P. N. Vovos, A. E. Kiprakis, R. A. Wallace, and G. P. Harrison, "Centralized and distributed voltage control: impact on distributed generation penetration," IEEE Transactions on Power Systems, vol. 22, no. 1, pp. 476-483, 2007.

[6] X. Liu, A. Aichhorn, L. Liu, and H. Li, "Coordinated control of distributed energy storage system with tap changer transformers for voltage rise mitigation under high photovoltaic penetration," IEEE Transactions on Smart Grid, vol. 3, no. 2, pp. 897-906, 2012.

[7] M. H. Bollen and N. Etherden, "Overload and overvoltage in low-voltage and medium-voltage networks due to renewable 
energy - some illustrative case studies," in 2011 2nd IEEE PES International Conference and Exhibition on Innovative Smart Grid Technologies, Manchester, UK, December 2011.

[8] M. B. Satti, A. Hassan, and M. I. Ahmad, "A new multilevel inverter topology for grid-connected photovoltaic systems," International Journal of Photoenergy, vol. 2018, Article ID 9704346, 9 pages, 2018.

[9] X. Su, M. A. S. Masoum, and P. J. Wolfs, "Optimal PV inverter reactive power control and real power curtailment to improve performance of unbalanced four-wire LV distribution networks," IEEE Transactions on Sustainable Energy, vol. 5, no. 3, pp. 967-977, 2014.

[10] T. L. Vandoorn, J. De Kooning, B. Meersman, and L. Vandevelde, "Voltage-based droop control of renewables to avoid ON-OFF oscillations caused by overvoltages," IEEE Transactions on Power Delivery, vol. 28, no. 2, pp. 845-854, 2013.

[11] D. V. Bozalakov, T. L. Vandoorn, B. Meersman, G. K. Papagiannis, A. I. Chrysochos, and L. Vandevelde, "Damping-based droop control strategy allowing an increased penetration of renewable energy resources in low-voltage grids," IEEE Transactions on Power Delivery, vol. 31, no. 4, pp. 1447-1455, 2016.

[12] M. Hartner, A. Ortner, A. Hiesl, and R. Haas, "East to west the optimal tilt angle and orientation of photovoltaic panels from an electricity system perspective," Applied Energy, vol. 160, pp. 94-107, 2015.

[13] D. H. W. Li and T. N. T. Lam, "Determining the optimum tilt angle and orientation for solar energy collection based on measured solar radiance data," International Journal of Photoenergy, vol. 2007, Article ID 85402, 9 pages, 2007.

[14] G. N. Tiwari and S. Dubey, Fundamentals of Photovoltaic Modules and their Applications, Springer, 2010.

[15] T. M. Klucher, "Evaluation of models to predict insolation on tilted surfaces," Solar Energy, vol. 23, no. 2, pp. 111-114, 1979.

[16] D. L. King, W. E. Boyson, and J. A. Kratochvill, "Photovoltaic array performance model," Sandia National Laboratories, Albuquerque, 2004.

[17] T. Huld, R. Gottschalg, H. G. Beyer, and M. Topič, "Mapping the performance of PV modules, effects of module type and data averaging," Solar Energy, vol. 84, no. 2, pp. 324$338,2010$.

[18] E. Lorenz, T. Scheidsteger, J. Hurka, D. Heinemann, and C. Kurz, "Regional PV power prediction for improved grid integration," Progress in Photovoltaics, vol. 19, no. 7, pp. 757-771, 2011.

[19] K. Mertens and K. F. Hanser, "Chapter 7, section 7.2.4 efficiency of inverters," in Photovoltaics: Fundamentals, Technology and Practice, pp. 177-181, Wiley, 2014.

[20] C. Demoulias, "A new simple analytical method for calculating the optimum inverter size in grid-connected PV plants," Electric Power Systems Research, vol. 80, no. 10, pp. 1197-1204, 2010.

[21] Project INCREASE, "Increasing the penetration of renewable energy sources in the distribution grid by developing control strategies and using ancillary, WP3, deliverable 3.1: dynamic equivalent models for the simulation of controlled DRES," 2014, http://www.project-increase.eu.

[22] W. Labeeuw and G. Deconinck, "Residential electrical load model based on mixture model clustering and Markov models,"
IEEE Transactions on Industrial Informatics, vol. 9, no. 3, pp. 1561-1569, 2013.

[23] “Open DSS simulation tool," http://sourceforge.net/projects/ electricdss.

[24] R. C. Dugan and T. E. McDermott, "An open source platform for collaborating on smart grid research," in 2011 IEEE Power and Energy Society General Meeting, Detroit, MI, USA, July 2011.

[25] G. C. Kryonidis, E. O. Kontis, A. I. Chrysochos et al., “A simulation tool for extended distribution grids with controlled distributed generation," in 2015 IEEE Eindhoven PowerTech, Eindhoven, Netherlands, June-July 2015.

[26] NREL, https://pvwatts.nrel.gov/.

[27] NREL, "PVWatts Version 5 Manual," October 2019, https:// www.nrel.gov/docs/fy14osti/62641.pdf.

[28] R. Perez, P. Ineichen, R. Seals, J. Michalsky, and R. Stewart, "Modeling daylight availability and irradiance components from direct and global irradiance," Solar Energy, vol. 44, no. 5, pp. 271-289, 1990.

[29] S. Zhou, C. Zhou, W. Wang et al., "Effect of subgrains on the performance of mono-like crystalline silicon solar cells," International Journal of Photoenergy, vol. 2013, Article ID 713791, 8 pages, 2013.

[30] D. V. Bozalakov, J. Laveyne, J. Desmet, and L. Vandevelde, "Overvoltage and voltage unbalance mitigation in areas with high penetration of renewable energy resources by using the modified three-phase damping control strategy," Electric Power Systems Research, vol. 168, pp. 283-294, 2019.

[31] CENELEC, EN 50160: Voltage Characteristics of Electricity Supplied by Public Electricity Networks, CENELEC, 2010.

[32] D. Bozalakov, M. J. Mnati, J. Laveyne, J. Desmet, and L. Vandevelde, "Battery storage integration in voltage unbalance and overvoltage mitigation control strategies and its impact on the power quality," Energies, vol. 12, no. 8, article 1501, 2019.

[33] D. Bozalakov, T. L. Vandoorn, B. Meersman, C. Demoulias, and L. Vandevelde, "Voltage dip mitigation capabilities of three-phase damping control strategy," Electric Power Systems Research, vol. 121, pp. 192-199, 2015. 